\title{
Meningkatkan Pemahaman Kalangan Pemilih Pemula Tentang Bahaya Politik Uang dalam Pilkada Sleman
}

\author{
SL. Harjanta \\ Prodi Administrasi Publik, FISIPOL \\ Universitas Widya Mataram \\ E-mail: harjantosulis@gmail.com
}

\begin{abstract}
Simultaneous regional elections will be held again in 2020. For the people of Sleman in September, they will join the democratic party again. One of the frauds in the Pilkada that must be watched out for is the use of money politics to win the battle for the seat of the regent and deputy regent of Sleman. Previous literature studies, the conclusions of many parties, stated that the 2014 Legislative Election and the simultaneous regional elections were an electoral political event full of money politics.

It is very important to instill an anti-money politics culture for new voters. With a large number of voters, first-time voters will determine the implementation of Pilkada and General Election. Beginner voters are also in a position to be easily influenced, including the lure of money politics. In the socialization that was held at Padukuhan Wonorejo, Sariharjo, Ngaglik, Sleman, there was a view that the practice of money politics was normal. With the aforementioned facts, the socialization of anti-money politics culture in Pilkada is very important. It is hoped that new voters will exercise their voting rights based on the candidate's program, not because of the lure of envelopes or money.
\end{abstract}

Keywords: money politics, new voters, legislative election

\section{ABSTRAK}

Pilkada serentak kembali dihelat pada tahun 2020 lalu. Ini juga yang dilakukan warga Sleman pada bulan September tahun lalu, yakni kembali mengikuti pesta demokrasi. Salah satu kecurangan dalam Pilkada yang harus diwasapadai adalah penggunaan politik uang untuk memenangkan pertarungan memperebutkan kursi bupati dan wakil bupati Sleman. Kajian literatur sebelumnya, kesimpulan banyak pihak menyatakan, jika Pemilihan Legislatif tahun 2014 maupun Pilkada serentak merupakan perhelatan politik elektoral yang sarat akan politik uang.

Menanamkan budaya anti politik uang sangat penting dilakukan pada para pemilih pemula. Dengan jumlah yang banyak, pemilih pemula akan menjadi penentu dalam penyelenggaraan Pilkada maupun Pemilu. Pemilih pemula juga dalam posisi yang mudah dipengaruhi, termasuk soal iming-iming politik uang. Dalam sosialisasi yang dilakukan di Padukuhan Wonorejo, Sariharjo, Ngaglik, Sleman tampak pandangan jika praktik politik uang merupakan hal yang wajar. Dengan beberapa fakta di atas kemudian sosialisasi tentang bahaya politik uang dalam Pilkada menjadi sangat penting. Diharapkan, para pemilih pemula menggunakan hak pilihnya berdasarkan program yang diusung oleh kandidat, bukan karena iming-iming amplop atau uang.

Kata Kunci : Politik Uang, Pemilih Pemula, Pilkada. 


\section{PENDAhuluan}

Pada tahun 2020 lalu, kembali dihelat Pilkada serentak. Bagi warga Sleman, pada bulan September saat itu mengikuti pesta demokrasi lima tahunan. Dalam Pilkada itu diikuti oleh tiga pasangan calon bupati dan wakil bupati. Pasangan pertama adalah Danang Wicaksana Sulistiya-Agus Choliq. Pasangan calon bupati dan wakil bupati ini diusung dari Partai Gerindra dan PKB. Pasangan kedua yakni Kustini Sri Purnomo-Danang Maharsa yang diusung PDIP dan PAN. Seperti diketahui, Kustini merupakan istri dari Bupati Sleman, Sri Purnomo. Sedangkan pasangan ketiga adalah Sri MuslimatunAmin Purnama yang diusung tiga partai. Yaitu Nasdem, Golkar dan PKS. Saat maju sebagai calon bupati, Sri Muslimatun merupakan Wakil Bupati Sleman. Berdasar data KPU Sleman, jumlah pemilih dalam Pilkada 2020 sebanyak 792.925 orang. Rinciannya, data pemilih Laki-laki 385.203 orang dan Perempuan 407.722 orang. Para pemilih ini tersebar di 2.125 Tempat Pemungutan Suara (TPS) di 17 kecamatan dan 86 desa/kelurahan.

Salah satu kecurangan dalam Pilkada yang harus diwaspadai adalah penggunaan politik uang untuk memenangkan pertarungan memperebutkan kursi bupati dan wakil bupati Sleman. Sebelum pelaksanaan Pilkada Sleman, Jogja Coruption Watch (JCW) menyoroti tentang adanya potensi politik uang. Potensi politik uang itu berbentuk bantuan sosial yang diberikan oleh pemerintah daerah (jogja.suara.com,1 Desember 2020). Soal potensi politik uang juga diwaspadai pihak Bawaslu Sleman. Lembaga pengawas pemilu ini mensinyalir praktik politik uang terjadi di TPS masing-masing calon (krjogja.com,1 Oktober 2019).

Kajian literatur sebelumnya, kesimpulan banyak pihak menyatakan, jika Pemilihan Legislatif tahun 2014 maupun Pilkada serentak merupakan perhelatan politik elektoral yang sarat akan politik uang. Dewan Kehormatan Penyelenggara Pemilu (DKPP) maupun Indonesia Corruption Watch (ICW) menyebut praktik politik uang maupun bentuk patronase yang lain terjadi secara masif dan brutal saat Pileg 2014 lalu (detiknews.com, 17 April 2014).

Namun sejumlah literatur menyebut jika sejak lama politik patronase mewarnai pemilu di Indonesia (Scott, 1972, Slater, 2004, Mietzner, 2007, Tomsa, 2008 : 
88, Ambardi, 2009 dan Stokes, 2013). Kandidat yang ingin terpilih, baik dalam pemilihan presiden, pemilihan anggota legislatif maupun pemilihan kepala daerah, menggunakan politik patronase sebagai bagain dari strategi pemenangan (Aspinall \& Sukmajati, 2015 :10). Merujuk pada Shefter, patronase dipahami sebagai sebuah pembagian keuntungan di antara politisi untuk mendistribusikan sesuatu secara individual pada para pemilih, para pekerja atau aktivis kampanye dalam rangka mendapatkan dukungan politik dari mereka (Shefter 1994: 238, n.3, lihat juga Hutchr 2014 :176-177). Dengan begitu, patronase merupakan pemberian uang tunai, barang, jasa dan keuntungan lainnya yang didistribusikan politisi pada individu mauapun pada kelompok/ komunitas. Patronase juga bisa berupa uang tunai atau barang yang didistribusikan pada pemilih yang berasal dari dana pribadi (misalnya dalam pembelian suara) atau dana publik (misalnya, proyek-proyek pork barrel yang dibiayai oleh pemerintah). Meskipun demikian, ada perbedaaan patronase dengan materi-materi yang sifatnya programatik (programmatic good). Yaitu, materi yang diterima oleh seorang yang menjadi target dari program-program pemerintah. Misalnya, program kartu pelayanan kesehatan yang menawarkan perawatan gratis untuk pendudukuk miskin (Aspinall \& Sukmajati, $2015: 4$ )

Dalam politik patronase juga erat kaitannya dengan klientelisme. Lebih jauh, patronase merujuk pada materi atau keuntungan lain yang didistribusikan oleh politisi kepada pemilih atau pendukung. Sebaliknya, klientelisme merujuk pada karakter relasi antara politisi dan pemilih atau pendukung. Klientelisme merupakan 'relasi kekuasaan yang personalistik' (Hutchcroft 2014 : 177), dengan keuntungan material dipertukarkan dengan dukungan politik. Hutchcroft merujuk pada tulisantulisan sebelumnya, terutama Scott (1972), menekankan bahwa relasi klientelistik adalah relasi tatap muka secara langsung (face to face). Selanjutnya, Hicken (2011) menjelaskan bahwa definisi klientelisme setidaknya mengandung tiga hal. Pertama, kontingensi atau timbal balik; 'pemberian barang atau jasa dari satu pihak (patron atau klien) merupakan respon langsung terhadap pemberian keuntungan dari pihak lain' (Hicken 2011:291). Biasanya, sumbersumber material dipertukarkan dengan suara atau bentuk dukungan politik lainnya. Kedua, hierarkis; ada penekanan pada relasi kekuasaan yang tidak seimbang atara patron 
dengan klien. Ketiga, aspek penanganan; pertukaran klientelistik berlangsung secara terus-menerus.

Politik uang potensial menyasar pemilih pemula yang tinggal di desa hingga wilayah urban. Tak hanya pada kalangan pemilih, politik uang bisa juga menyasar penyelenggaraan atau panitia pemilihan hingga tingkat bawah. Dengan begitu, pengabdian masyarakat ini mengambil lokasi di Dukuh Wonorejo, Desa Sariharjo, Kecamatan Ngaglik, Kabupaten Sleman. Meski berstatus desa, Sariharjo adalah sebuah wilayah urban dengan jumlah penduduk padat dan beragam profesi. Selain itu, banyak pemuda di sana yang juga menjadi panitia pemilihan di tingkat TPS (KPPS) maupun jadi saksi. Selanjutnya, rumusan masalah dalam pengabdian masyarakat ini adalah sejauh mana pemuda Wonorejo, Sariharjo, Ngaglik, Sleman memahami jenis dan bahaya politik uang dalam Pilkada Sleman? Sementara itu, tujuan dari pengabdian ini adalah meningkatkan pemahaman pemuda Wonorejo tentang bahaya politik uang dalam Pilkada. Diharapkan, pengabdian pada masyarakat ini bisa menciptakan pilkada yang bersih, terbebas dari praktik politik uang.

\section{METODE PELAKSANAAN PENGABDIAN}

Pengabdian pada masyarakat ini menyasar kelompok pemilih pemula di Wonorejo, Sariharjo, Ngaglik, Sleman. Alasan dipilihnya pemuda di sana, karena organisasi karang taruna setempat cukup aktif. Kendati begitu, mereka belum memiliki pemahaman yang komprehensif terkait praktik politik uang dan bahayanya bagi demokrasi.

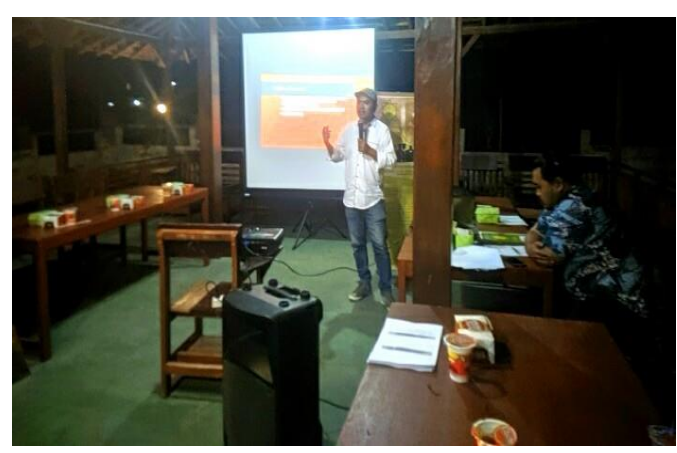

Gambar 2.1

Sosialisasi Membentuk Budaya Anti Politik Uang

Metode yang digunakan dalam kegiatan pengabdian masyarakat ini adalah:

1. Ceramah

Penyuluh memberikan ceramah mengenai hal-hal yang berkaitan dengan praktik politik uang dalam Pilkada

\section{Bahan Serahan (Hand Out)}

Di samping mendengarkan ceramah, para peserta diberikan bahan berupa hand-out/ makalah sederhana. Hal ini dimaksudkan 
untuk memudahkan dan memperjelas penyampaian dan sebagai bahan tambahan pengetahuan bagi para peserta.

\section{Tanya jawab}

Setelah disampaikan materi penyuluhan kemudian dilanjutkan dengan tanya jawab antara penyuluh dan peserta.

\section{HASIL DAN PEMBAHASAN}

Praktik politik uang dalam Pemilu termasuk Pilkada begitu mengakar. Di sebagian besar kalangan pemilih menilai, praktik politik uang dianggap hal yang biasa. Demikian mengacu pada sejumlah hasil riset atau kajian tentang politik uang (Aspinal: 2014). Pandangan ini juga diperkuat dalam kegiatan pengabdian masyarakat dengan tema 'Meningkatkan Pemahaman Pemilih Pemula Terhadap Bahaya Politik Uang dalam Pilkada'. Dalam acara yang berlangsung 29 Juli 2020 di Pendopo Padukuhan Wonorejo, Sariharjo, Ngaglik, Sleman ini, diikuti para pemilih pemula. Dalam dialog awal, muncul pandangan bahwa serangan fajar atau pemberian uang dari kandidat pada pemilih dianggap sebagai sebuah hal yang wajar.

Dengan adanya pandangan yang menganggap praktik politik uang sebagai hal yang lumrah maka sosialisasi dengan tema bahaya politik uang dalam Pilkada menjadi penting. Alasan selanjutnya, pada Desember 2020 berlangsung Pilkada. Di mana, sebagian besar pemilih merupakan pemilih pemula. Sosialisasi ini menyasar pemuda Padukuhan Wonorejo yang sebagian besar mereka adalah pemilih pemula dalam Pilkada Desember 2020 mendatang. Bahkan beberapa anggota karang taruna, merupakan anggota pemilihan di tingkat TPS maupun KPPS. Dengan begitu, pemahaman tentang bahaya politik uang bagi pemilih dan juga panitia Pilkada menjadi sangat penting.

Pelaksanaan sosialisasi dapat dilihat dokumentasi foto di bawah ini :

Gambar 3. 1

Sosialisasi Tentang Politik Uang

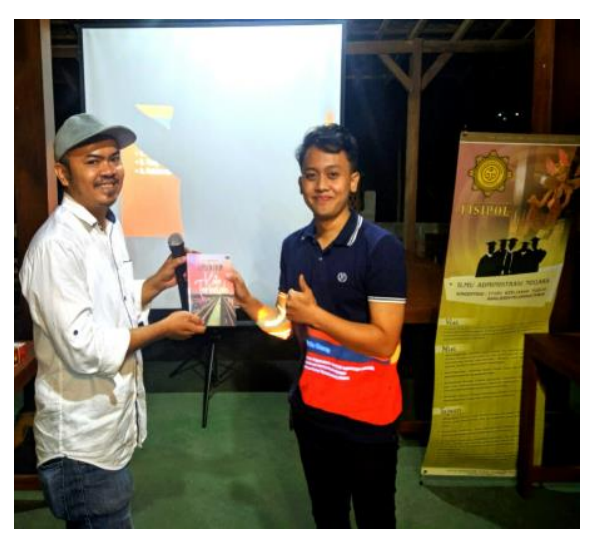




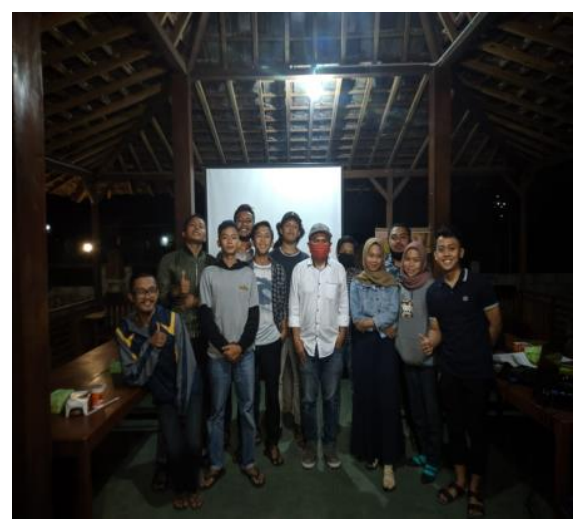

Dari dokumentasi di atas tampak sosialisasi berlangsung akrab dan cair. Di tengah suasana pandemi Covid 19, para peserta duduk di bangku yang disusun berbentuk huruf $U$ dengan tetap menjaga jarak. Sementara pemateri berada di depan menjelaskan tentang bahaya politik uang. Ada beberapa hal yang dijelaskan dalam sosialisasi itu. Yakni diawali dari penyampaikan tentang problematika penyelenggaraan Pemilu termasuk Pilkada didalamnya. Ada beberapa problem dalam penyelenggaraan Pilkada, yaitu soal masalah sosial, struktural, finansial hingga politik uang. Problem sosial terkait dengan konflik antar pendukung yang dipicu persaingan dalam Pilkada. Beberapa daerah di Indonesia mengalami konflik ini saat perhelatan Pilkada. Sedangkan problem struktur terkait dengan pelanggaran yang dilakukan oleh penyelenggara Pemilu atau pun Pilkada. Sementara itu, masalah finansial terkait dengan besarnya biaya penyelenggaran Pilkada serentak. Dan yang terakhir yakni terkait dengan praktik politik uang.

Praktik politik uang menjadi penekanan dalam sosialisasi tersebut. Soal penjelasan politik uang ini dimulai dari jenis-jenis, faktor penyebab hingga dampak dari politik uang. Dalam teori politik uang dikenal dengan istilah politik patronase. Mengacu pada pendapat Aspinal (2014), politik patronase adalah pemberian oleh kandidat pada pemilih. Pemberian itu dengan harapan mendapat dukungan dari pemilih. Setidaknya ada empat bentuk politik patronase. Pertama, vote buying, merupakan pertukaran langsung antara uang, barang atau pelayanan dengan dukungan suara pada pemilihan. Kedua, club goods, merupakan pembelian kompensasi berupa materi yang ditujukan pada kelompok atau komunitas pemilih. Ketiga, pork barel, merupakan pemberian proyek pada daerah atau dimana patron dipilih. Keempat, programmatic goods, merupakan strategi pemberian melalui sumber daya Negara dimana kalkulasi politik, biaya atau pelayanan diperoleh secara programmatic, biasanya berupa program pengentasan kemiskinan.

Sementara itu, politik uang dipicu 
oleh beberapa faktor. Faktor itu adalah mulai dari biaya politik mahal, politik oligharki, budaya pragmatism dan lemahnya penindakan hukum atas praktik politik uang. Dalam kesempatan itu juga dijelaskan terkait dengan dampak politik uang. Beberapa dampak itu adalah. APBD berpotensi digunakan untuk kepentingan pemodal hingga terpilihnya pemimpin yang tidak kompeten. Penjelasan tentang APBD berpotensi diselewengkan karena kandidat dalam proses Pilkada mengeluarkan uang yang besar. Umumnya, biaya politik itu merupakan sumbangan dari sejumlah pihak. Ada istilah tidak ada makan siang gratis. Jadi para pemodal itu mengharapkan mendapatkan pengembalian berupa proyek pemerintah (Pemda). Selain risiko penyelewengan APBD, kepala daerah yang terpilih berpotensi orang yang tidak kompeten. Ini karena dia terpilih dengan kekuatan uang, bukan keunggulan program.

Setelah memberikan pemaparan, acara kemudian dilanjutkan diskusi. Peserta cukup antusias melontarkan beberapa pertanyaan maupun pendapat. Secara umum, para peserta mengaku mendapatkan pemahaman baru terkait bahaya politik uang dalam Pilkada.
Dari hasil pengabdian ini mendapatkan beberapa kesimpulan. Pertama, banyak kalangan pemilih pemula di Dusun Wonorejo, Sariharjo, Ngaglik, Sleman belum mengetahui tentang bentuk atau jenis-jenis politik uang. Bagi sebagian pemilih, mendapatkan pemberian dari kandidat dianggap sebagai hal biasa. Padahal pemberian itu termasuk bentuk politik uang. Kedua, banyak kalangan pemilih pemula yang tidak mengetahui akan bahaya politik uang. Baik bagi demokrasi maupun pada penyelenggaraan pemerintahan setelah Pilkada.

Kenyataan bahwa pemahaman akan bahaya politik uang ini makin kuat, maka upaya menanamkan kesadaran bagi kalangan pemilih pemula harus terus dilakukan. Partai politik menjadi pihak utama dalam proses ini. Dalam hal ini, partai politik harus memulai dahulu untuk menghapuskan praktik pembelian suara ini. Kemudian setelah itu turut memberikan edukasi terhadap pemilih pemula. Pihakpihak lainnya, khususnya KPU dan juga Bawaslu terus melakukan sosialisasi sekaligus melakukan penindakan terhadap pelaku maupun penerima politik uang.

\section{DAFTAR PUSTAKA}

\section{PENUTUP}


Ambardi, Kuskrido, Mengungkap Politik Kartel, Strategi Tentang Sistem Kepartaian di Indonesia Era Reformasi, Kepustakaan Populer Indonesia, Jakarta, 2009

Aspinal, Edward, Politik Uang di Indonesia, Patronase dan Klientelisme di Pemilu Legislatif, Polgov UGM, Yogyakarta, 2014.

-----------, Sukmajati, 2015.Politik Uang di Indonesia: Patronase dan Klientelisme pada Pemilu Legislatif 2014 [Money Politics in Indonesia: Patronage and Clientelism in the 2014 Legislative Election], Research Centre for Politics and Government vol: issue : 2015 .

Hicken, A. Clientelism. Annual Review of Political Science 14, 289-310, 2011.

Hutchcroft, P. Linking capital and countryside: Patronage and clientelism in Japan, Thailand and The Philipines. In Brun, D.A., \& Diamond, L. (Ed), Clientelism, Social Policy and The Quality Democracy, (pp 174-203). University Press, 2014.

Mietzner, M. Party-financing in postSoeharto Indonesia: Between state subsidies and political corruption. Contemporary

Southeast Asia, 29(2), 238-263, 2007.
Scott, J.C. Patron-client politics and political change in Southeast Asia. American Political Science Review, 66(1), 91-113, 1972.

Shefter, M. Political parties and the state: The American historical experience. Princeton: Princeton University Press, 1994.

Slater, D. Indonesia's accountability trap: Party cartels and presidential power after democratic transition, 61-69, 2004.

Stokes, S. C., Dunning, T., Nazareno, M., Brusco, V. (2013). Brokers, voters, and clientelism: The puzzle of distributive politics. Cambridge, UK: Cambridge. 